\title{
Association of Taiwan's Rainfall Patterns with Large-Scale Oceanic and Atmospheric Phenomena
}

\author{
Yi-Chun Kuo,, Ming-An Lee, ${ }^{1,2,3}$ and Mong-Ming $\mathrm{Lu}^{4}$ \\ ${ }^{1}$ Department of Environmental Biology and Fisheries Science, National Taiwan Ocean University, 2 Pei-Ning Road, \\ Keelung 20224, Taiwan \\ ${ }^{2}$ Center of Excellence for Oceans, National Taiwan Ocean University, 2 Pei-Ning Road, Keelung 20224, Taiwan \\ ${ }^{3}$ Taiwan Group on Earth Observations, Zhubei, Hsinchu County 30274, Taiwan \\ ${ }^{4}$ Research and Development Center, Central Weather Bureau, Taipei, Taiwan
}

Correspondence should be addressed to Ming-An Lee; malee@ntou.edu.tw

Received 30 January 2015; Revised 27 April 2015; Accepted 18 May 2015

Academic Editor: Jean-Pierre Barriot

Copyright (C) 2016 Yi-Chun Kuo et al. This is an open access article distributed under the Creative Commons Attribution License, which permits unrestricted use, distribution, and reproduction in any medium, provided the original work is properly cited.

A 50-year (1960-2009) monthly rainfall gridded dataset produced by the Taiwan Climate Change Projection and Information Platform Project was presented in this study. The gridded data $(5 \times 5 \mathrm{~km})$ displayed influence of topography on spatial variability of rainfall, and the results of the empirical orthogonal functions (EOFs) analysis revealed the patterns associated with the large-scale sea surface temperature variability over Pacific. The first mode (65\%) revealed the annual peaks of large rainfall in the southwestern mountainous area, which is associated with southwest monsoons and typhoons during summertime. The second temporal EOF mode $(16 \%)$ revealed the rainfall variance associated with the monsoon and its interaction with the slopes of the mountain range. This pattern is the major contributor to spatial variance of rainfall in Taiwan, as indicated by the first mode (40\%) of spatial variance EOF analysis. The second temporal EOF mode correlated with the El Niño Southern Oscillation (ENSO). In particular, during the autumn of the La Niña years following the strong El Niño years, the time-varying amplitude was substantially greater than that of normal years. The third temporal EOF mode (7\%) revealed a north-south out-of-phase rainfall pattern, the slowly evolving variations of which were in phase with the Pacific Decadal Oscillation. Because of Taiwan's geographic location and the effect of local terrestrial structures, climate variability related to ENSO differed markedly from other regions in East Asia.

\section{Introduction}

Taiwan is located at the western edge of the Pacific Ocean with the Northern Tropic running through the island. Taiwan is one of the world's most mountainous islands and has five parallel mountain ranges that run roughly NNE-SSW. The Central Mountain Range (CMR) has five peaks with elevation above 3,500 $\mathrm{m}$ including Taiwan's highest peak YuShan, 3,952 $\mathrm{m}$ (Figure 1). The climate of Taiwan is dominated by the East Asian monsoons, which bring northeasterly winds in winter and southwesterly winds in summer. The high mountain ranges make Taiwan's climate vary regionally, most notably in precipitation.

The southwesterly monsoon (from May to August) brings heavy rainfall to southwestern Taiwan, and the northeasterly monsoon (from September to April) causes rainfall over the northeastern part of the island [1,2]. Moreover, from mid-May to mid-June (Mei-Yu season), frontal systems from southern China and the convective systems embedded within the southwesterly monsoon flow frequently bring heavy rainfall [3]. From summer until fall, typhoons bring heavy rainfall to Taiwan. Wang et al. [4] divided the rainfall regimes in Taiwan into five categories: spring rain period (March and April), Mei-Yu period (May and June), summer rain period (July, August, and September), autumn rain period (October and November), and winter rain period (December, January, and February).

The rainfall pattern in Taiwan is complex because of the presence of the CMR. Yen and Chen [5] reported that, under the influence of the CMR, the basic seasonal variation of Taiwan rainfall between the southwesterly monsoon and the northeasterly monsoon is generated by a counterclockwise 


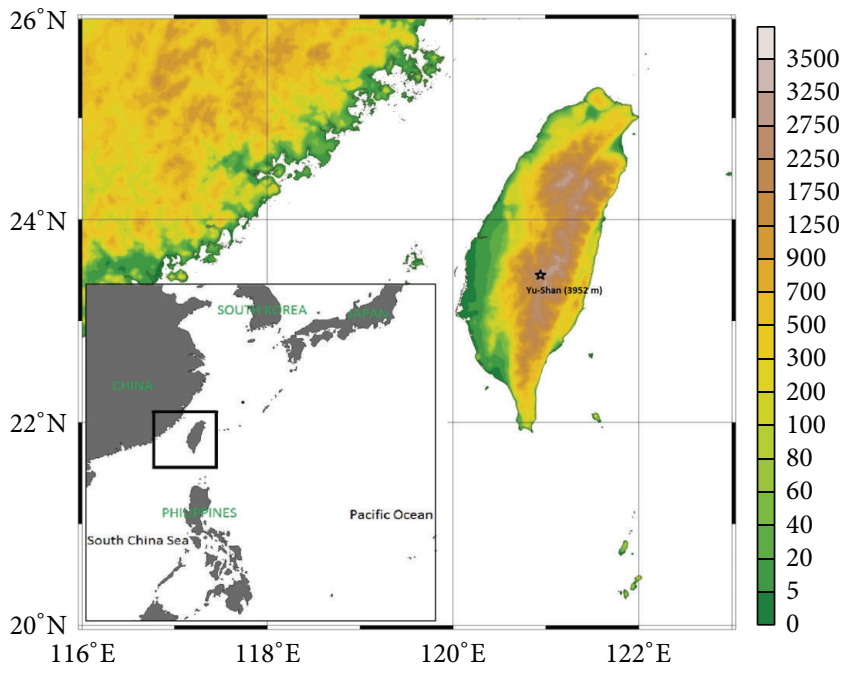

(a)

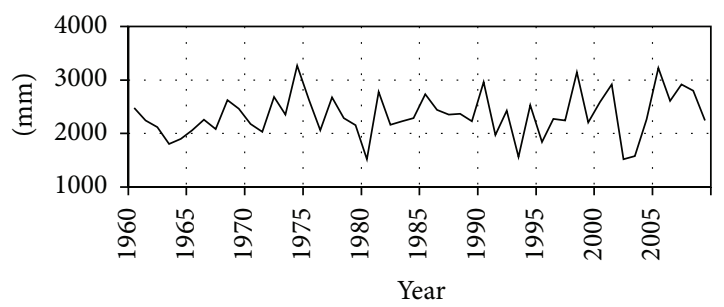

(c)

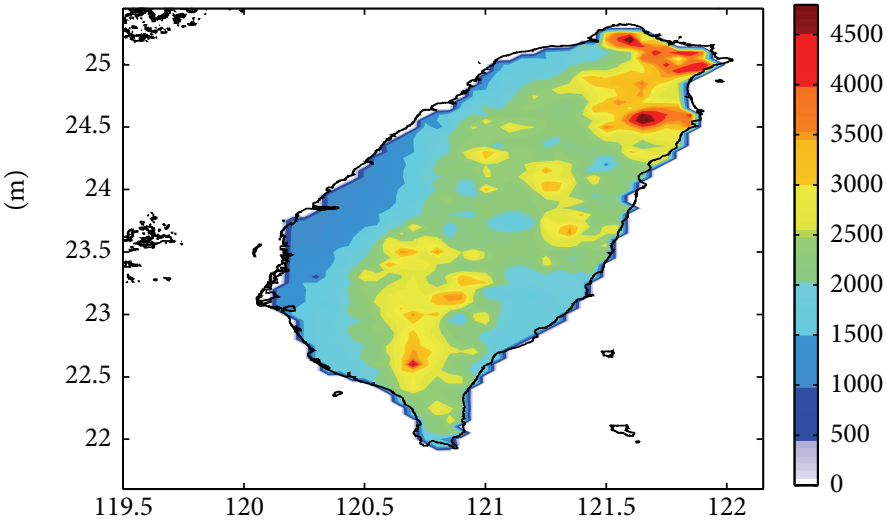

(b)

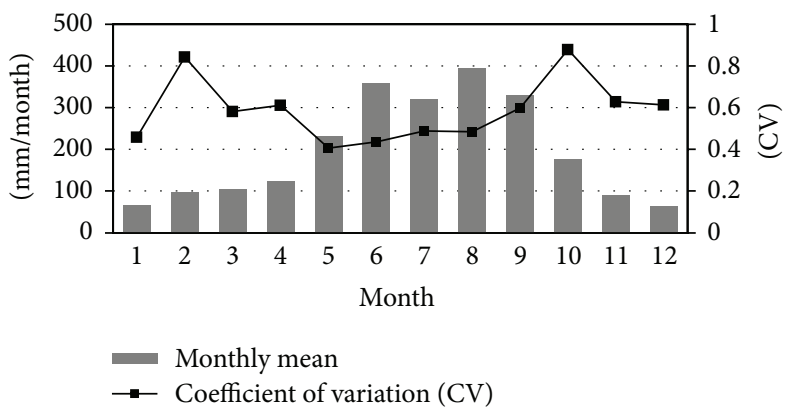

(d)

FIGURE 1: (a) The topography of Taiwan. (b) Distribution of annual rainfalls (mm/year) in Taiwan. (c) Variations in average annual rainfall over Taiwan during 1960-2009. (d) Variation in average monthly rainfall and the coefficient of variation (CV) of the averages over Taiwan during 1960-2009.

rotation of four rainfall regimes around Taiwan over a one-year cycle. Yeh [6] reported that typhoon rainfall in mountainous areas is enhanced as a result of the interaction of typhoons with the topography.

The large-scale variation of ocean-atmosphere interaction could be a remote driver of climate variability in Taiwan. Wang et al. [7] demonstrated that ENSO affects the climate in East Asia by causing an anomalous lower-tropospheric anticyclonic circulation around the Philippine Sea during the El Niño peak phase (from winter to ensuing spring). The anomalies sometimes persist into early summer and affect the rainfall in the East Asian subtropical front (the Mei-Yu season). Wang and Chan [8] compared tropical storm activity over the western North Pacific between La Niña and the stronger El Niño, suggesting a significant difference of life span and occurrence of TC in southeast and northwest quadrant of the western North Pacific. Jiang et al. [9] determined that rainfall during February-March is more and less than average following El Niño and La Niña peak phases, respectively. On a decadal scale, the warm/cold phase of the PDO (Pacific Decadal Oscillation) enforces the southwesterly/northeasterly anomalous winds to the east of Taiwan during spring time (February-April) and this anomaly was related to spring rainfall variability in northern Taiwan [10]. J.-M. Chen and H.-S. Chen [11] observed a relationship between the PDO and interdecadal variability of summer rainfall in Taiwan. They suggested the large-scale SST anomalies associated with warm phase of PDO induced a low-level anomalous cyclonic circulation over the subtropical western Pacific. The northeasterly on the western edge of the anomalous cyclone reduced moisture transport from the South China Sea into Taiwan, resulting in less seasonal rainfall. However, because of the complex topography, the interannual and decadal variability in the rainfall pattern in Taiwan remain unclear.

A comprehensive understanding of the spatial and temporal variations in precipitation is required for improving the use of water resources and for planning diverse human 
activities. In this study, we analyzed the gridded monthly precipitation data, obtained at a $5 \mathrm{~km}$ spatial resolution and collected from thousands of stations between 1960 and 2009 , in order to comprehensively understand the spatial and temporal variations in rainfall and to reveal the long-term variation of rainfall in Taiwan. The results of our analyses identified the patterns associated with large-scale climate variability. In Section 2, we briefly describe the rainfall data and, in Section 3, we describe the results of empirical orthogonal function (EOF) analysis and their relationships with large-scale climatic variations. We discuss our findings and present our conclusions in Sections 4 and 5, respectively.

\section{Data and Methods}

The long-term gridded precipitation dataset was collected by the TCCIP (Taiwan Climate Change Projection and Information Platform Project; http://tccip.ncdr.nat.gov.tw/NCDR/ main/index.aspx). The TCCIP has filtered observation data from more than 1,500 rain gauges through a homogeneous process, of which 1,187 are used to produce the gridded data. The original precipitation data were obtained from meteorological stations from the Central Weather Bureau, the Water Resources Agency, the Ministry of Economic Affairs, Irrigation Associations, and the Taiwan Power Company. Gaps in the data were filled with interpolated data by using the stations' spatial information to create a complete time series at each station. The weighting factors of station data are the functions of distance, elevation difference, and relative angular distribution with respect to the series under consideration [12]. To minimize errors caused by missing data, we included only the stations that have collected data over a period of longer than 20 days in one month. Monthly data were calculated as $\left(\sum_{i=1}^{n} X_{i} / n\right) * d(\mathrm{~mm} / \mathrm{month})$, where $n$ is the total days of available data, $X_{1}, X_{2}, \ldots, X_{n}$ represent the daily precipitation data, and $d$ is the total number of days in a month. The gridded method used here was based on Glasbey and Nevison [13], and the latent Gaussian variable (LGV) was used to avoid problems of singularity on days without rain and of a long upper tail in the case of daily rainfall data [14]. The final product featured a grid size of $5 \times 5 \mathrm{~km}$.

Figure 1(b), the distribution of annual rainfall averaged over 50 years, indicates that the rainfall is typically higher in mountain areas than in other parts of the island. Maximal rainfall occurs in the northeastern corner of Taiwan, reaching $4,000 \mathrm{~mm}$ annually, whereas the driest part is in the central west of the island, which receives roughly $1,000 \mathrm{~mm}$ of rain annually. The variation of annual rainfall is plotted in Figure 1(c). The annual accumulated-rainfall over the island varies substantially from year to year. It varies from 1600 to $3100 \mathrm{~mm}$ but the average is approximately $2,400 \mathrm{~mm}$. The average annual variation and its coefficient of variation (CV) are plotted in Figure $1(\mathrm{~d})$. The monthly rainfall peak is in August, and a second peak is in June. However, the variation is much larger in autumn and winter than in other seasons, as shown by the CV (Figure 1(d)). In order to identify the temporal variance that dominates the spatial structure, monthly rainfall variance during 1960-2009 was further investigated using the EOF method.
EOF analysis can help efficiently synthesize the information contained in physical quantities that vary spatially and temporally. In this approach, the data field is represented as the sum of a small number of orthogonal modes and the associated temporally varying amplitude (PCs). Temporal or spatial EOF analysis is performed by diagonalizing the covariance matrix to remove the spatial or temporal mean from the data. The amplitude function is calculated by projecting the data onto the orthogonal mode. Using this method facilitates the identification of physically and dynamically independent patterns. Temporal (spatial) EOF analysis generates a set of modes that explain fractions of temporal (spatial) variance. Thus, we can identify the temporal variance that dominates a spatial structure or the spatial variance that dominates the temporal variance of a spatial structure.

To detect the periodicity features of the PCs, the continuous wavelet transform (CWT) method was used in the current study. The Morlet wavelet, which provides a favorable balance between time and frequency localization, was applied. The cone of influence (COI) is the region of the wavelet spectrum in which edge effects become critical and is defined here as the e-folding time for the autocorrelation of wavelet power at each scale. A confidence level of $95 \%$ was adopted as the threshold at which to classify the significance of the wavelet power. Detailed information of the continuous wavelet transform used in the current study was introduced in-depth by Torrence and Compo [15].

To assess the association of the regional rainfall pattern with global SST changes, the gridded data $\left(1^{\circ} \times 1^{\circ}\right)$ of monthly SSTs between 1960 and 2009 were retrieved from the UK Met Office Hadley Centre SST Climatology HadISST1 [16]. Monthly $850 \mathrm{mb}$ winds data were obtained from the National Centers for Environmental Prediction (NCEP) reanalysis data, provided by NOAA/OAR/ESRL PSD (http://www.esrl.noaa.gov/psd/data/gridded/data.ncep.reanalysis.html).

The correlation coefficient between rainfall variance and the Nino 3.4 and PDO indices was computed in the study. Nino 3.4 (retrieved from http://www.cpc.noaa.gov/data/ indices/) is the average sea surface temperature anomaly in the region bounded by $5^{\circ} \mathrm{N}$ to $5^{\circ} \mathrm{S}$, from $170^{\circ} \mathrm{W}$ to $120^{\circ} \mathrm{W}$. The US National Oceanic and Atmospheric Administration (NOAA) proposed an operational definition of El Niño that is based on a 3-month average of Niño 3.4 SST anomalies greater than or equal to $0.5^{\circ} \mathrm{C}$. The PDO (Pacific Decadal Oscillation) index derived as the leading principal component of monthly SST anomalies in the North Pacific Ocean was downloaded from http://research.jisao .washington.edu/pdo/PDO.latest.

\section{EOF Result}

3.1. Temporal EOF Result. The first three modes of EOF that were applied to the monthly gridded data collected between 1961 and 2009 can explain up to $87 \%$ of the total variance. Figures 2 and 3 depict the modes and their corresponding temporally varying amplitudes (PCs). The fourth mode contributed to $<3 \%$ of the total variance and was regarded as 


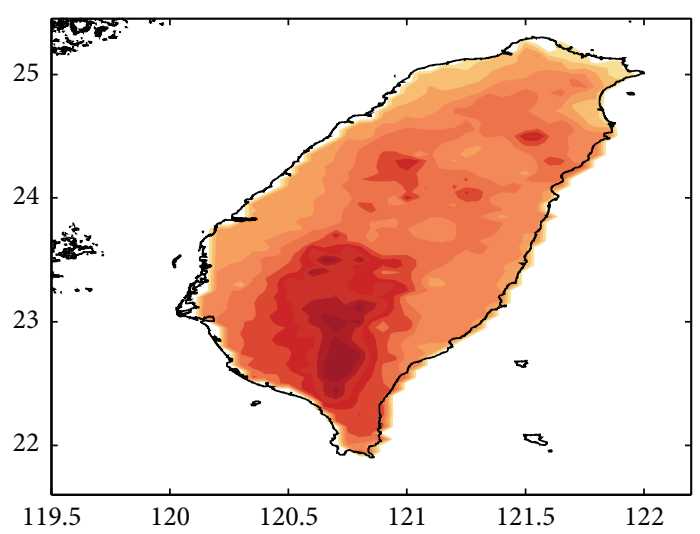

(a)
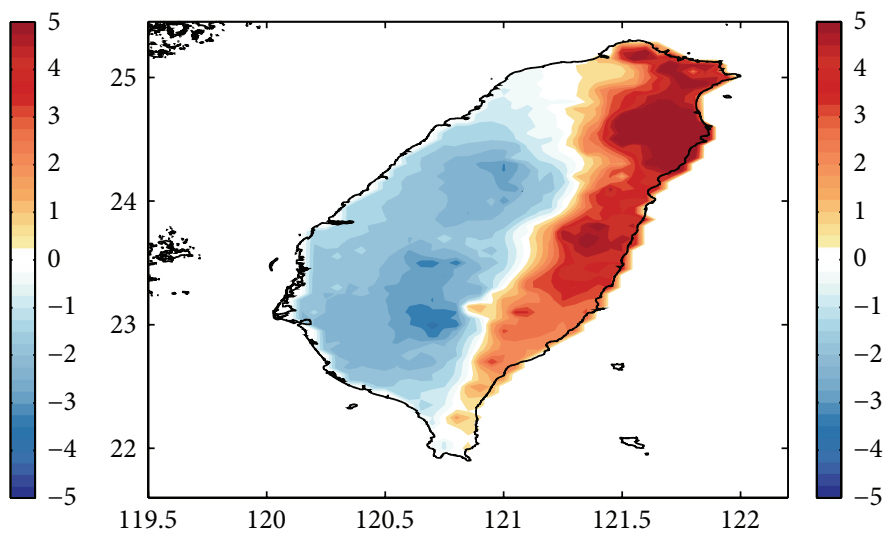

(b)

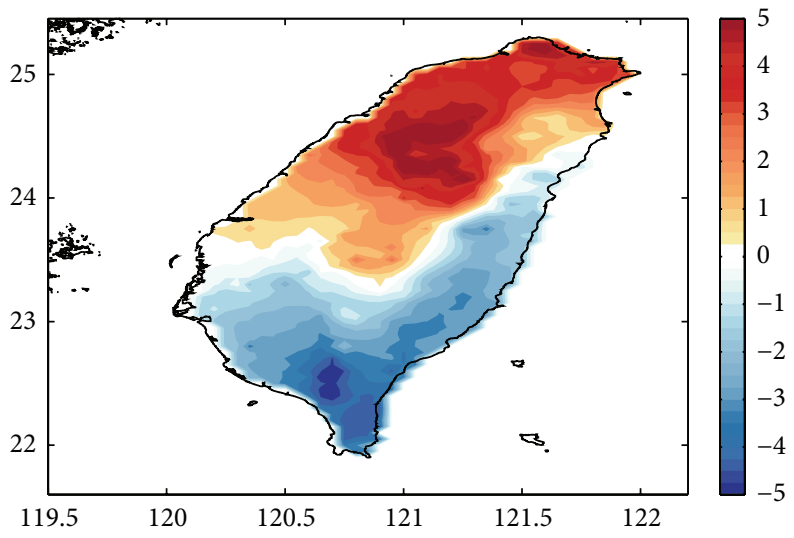

(c)

Figure 2: (a)-(c) Temporal EOF mode 1, mode 2, and mode 3 patterns.

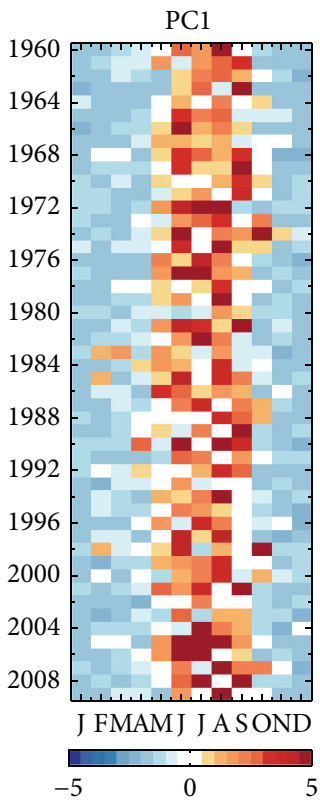

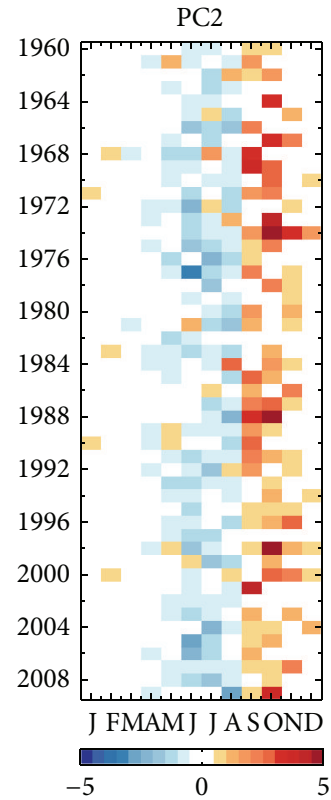

(a)
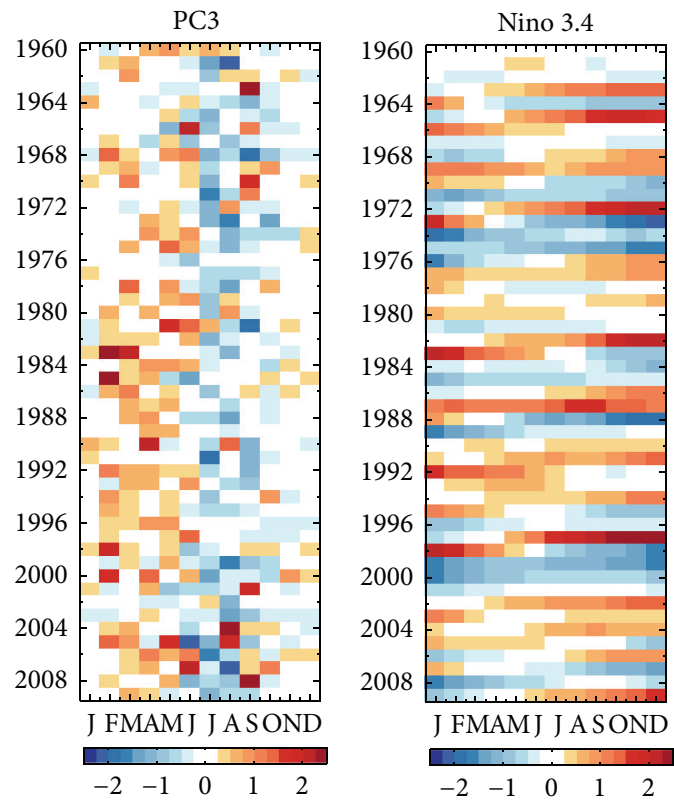

(b)

Figure 3: (a) The respective time-varying amplitude in the temporal EOF result. (b) Nino 3.4 index during 1960-2009. The Nino 3.4 index was retrieved from http://www.cpc.noaa.gov/data/indices/. 

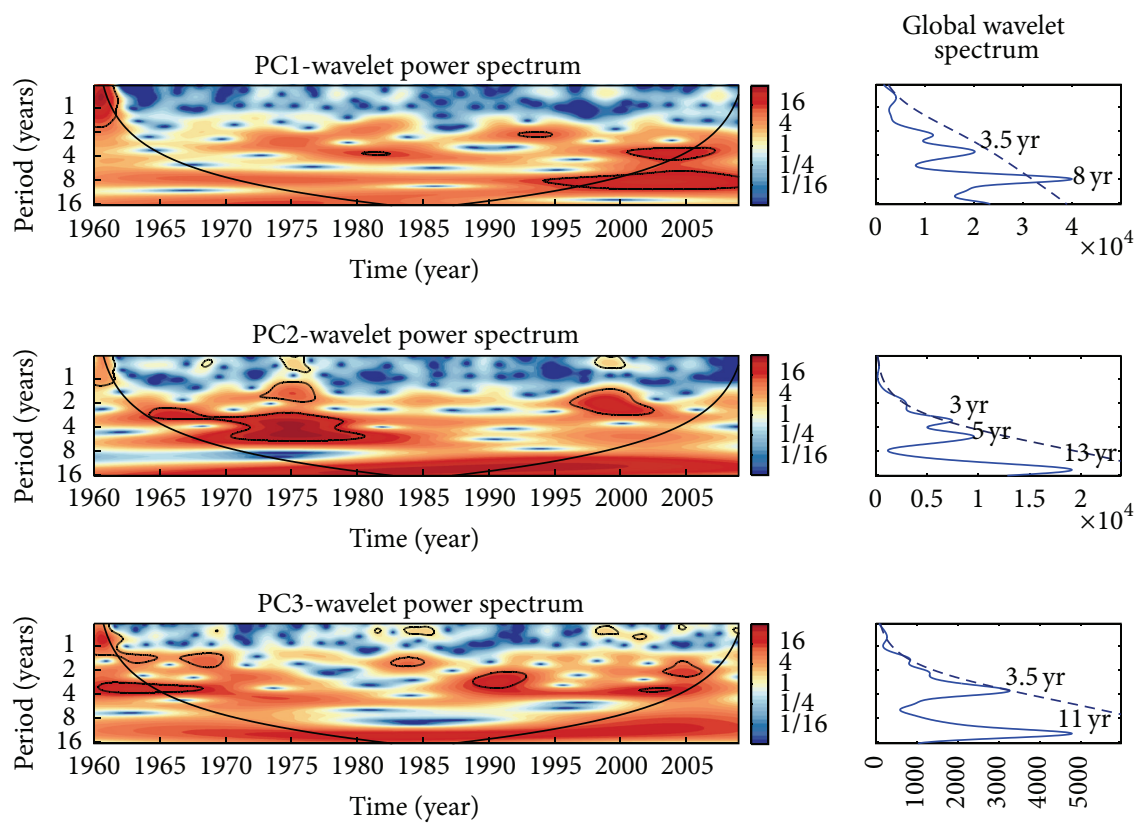

Figure 4: Results of wavelet analyses for PC1-PC3. The solid black contours show regions of greater than 95\% confidence. The bowl-shaped line constitutes the cone of influence. For the global wavelet spectrum, periods corresponding to the peaks are indicated.

noise. The first mode, which accounted for $65 \%$ of the total variance, exhibited a spatially coherent in-phase pattern, with the highest rainfall values concentrated in the southwestern mountain area. The similarity between Figures 1(b) and 2(a) suggests that EOF1 captures the areas with large annual rainfalls except the northeastern part of the island which receives the largest amount of annual rainfall totals. The dissimilarity over the northeastern part of the island can be explained by EOF2 which shows that a substantial portion of the rainfall variance over northeast Taiwan is negatively correlated with the rains over the southern range of the CMR. In other words, the annual rainfall totals over the northeast and southwest Taiwan do not always vary coherently. The loading amplitudes of these two modes (Figure 3) clearly show the difference in their seasonality. EOF1 mainly captures the variations of the rainfall amount accumulated during the wet season from May to September, associated with southwesterly monsoons and typhoons during Mei-Yu and summer period. Because Figure 1 (annual mean) and Figure 2(a) (first EOF) are similar, the seasonal cycle is mainly a variation around the annual mean. In addition, EOF1 contains interannual variation. EOF2 captures the contrast variations of the rainfall amount accumulated during September-November (positive loading amplitude) and June-August (negative loading amplitude); EOF2 shows that northeast Taiwan receives more rainfall compared to southwest Taiwan during SeptemberNovember and the contrast is opposite during June-August. Consequently, the annual mean and the seasonal cycle are mainly spatially controlled by mountains.

The interannual variation of the PC2 was strongest in autumn and it appeared to exhibit the signal of a strong ENSO (El Niño Southern Oscillation). Based on using the Nino 3.4 index (Figure 3(b)), we can conclude that the PC2 grew considerably during the La Niña years that followed strong El Niño years (1973-1974, 1988, and 1998). The third mode accounted for only $7 \%$ of the total variance and depicted a north-south out-of-phase pattern. The seasonal characteristics of the PC3 suggest that the contrast between north and south Taiwan is sharpest during the peak summer months. Sharp contrast can also be found during other time of a year, but the interannual variation is quite large. The PC3 typically showed positive values between February and May and negative ones during the other months. Decadal variation was observed in the positive phase of the third-mode time series and it increased around 1980.

To find periodicities greater than a year, the results of wavelet transform for the PCs are shown in Figure 4. A $12 \mathrm{~m}$ moving averaged was applied to remove the seasonal cycles. For PC1, higher power occurred in the $3.5 \mathrm{y}$ and $8 \mathrm{y}$ bands, although it was nonsignificant until 1995. Significant wavelet power can be observed in the 3-5 y band around 1965-1980 and 1995-2002 in PC2. A main periodicity of $11 \mathrm{y}$ can also be observed in PC2. PC3 exhibited a 3.5 y cycle around 1990. Three main periodicities of $3.5 \mathrm{y}$ and $11 \mathrm{y}$ can be observed in the PC3.

\subsection{The Relationship of the Leading Temporal EOF Modes} with the SST and Low-Level Wind Field. In Figure 5(a), we plot the linear-regression map of global annual average SSTs against the annual average first-mode component of the EOF. The F-test was used to evaluate the significance of linear-regression coefficients. Because the seasonal variation was filtered out, the correlation between the first EOF and SSTs was not significant. Figure 5(b) is a plot of the linearregression map of the global annual average SSTs against the annual average second-mode component of the EOF. 


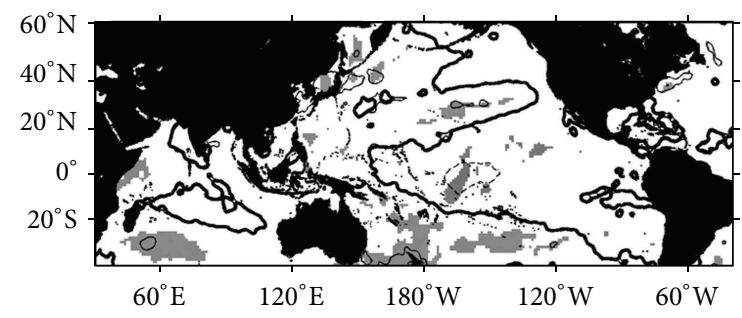

(a)

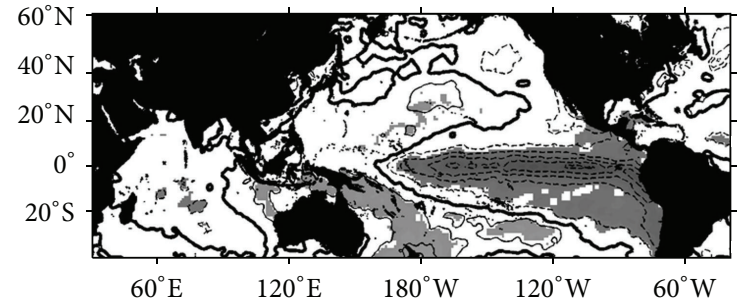

(b)

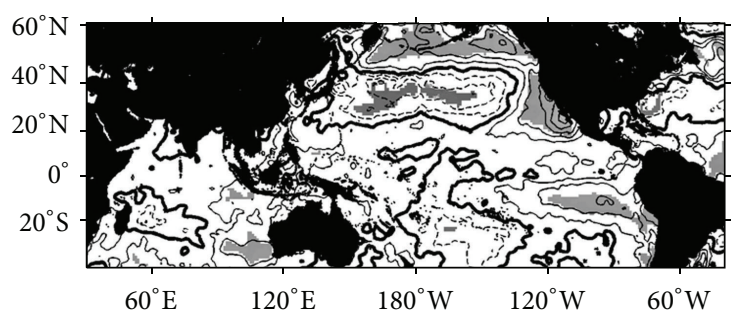

(c)

FIGURE 5: Regression maps of global annual average SST against (a) the first EOF, (b) the second EOF, and (c) the third EOF. The contour interval is $0.3^{\circ} \mathrm{C}$. Shaded areas exceed the $90 \%$ confidence level. The solid lines and dashed lines are the positive and negative values, respectively. The thickened lines represent the value 0 .

The overall pattern resembled the SSTA corresponding to ENSO events, revealing average SST warming and cooling across the central and eastern Pacific. Furthermore, the influence of the SST in the southern hemisphere was stronger than that in the northern hemisphere. The relationship between PC2 and ENSO is consistent with the wavelet analysis results (Figure 4), which demonstrated a 3-5 y cycle. Figure 5(c) shows a plot of the linear-regression map of the global annual average SSTs against the annual average third-mode component of the EOF. The pattern reveals a strong SST variation in the midlatitude region. This indicated a growing (decreasing) third-mode variance, representing a positive (negative) rainfall anomaly in northern Taiwan, which might be associated with a positive (negative) PDO phase. Studies have found that the variability of the Asian monsoon might play an active rather than passive role in tropical ENSO events. Conversely, ENSO events influence East Asian monsoons and have a systematic evolution associated with the annual cycle. To demonstrate the lead-lag relationship between EOF2 and ENSO, the lagged correlations of the PC2 with the Nino 3.4 index in the preceding and following months are plotted in Figure 6. A 2 mo running mean was applied to the EOF2 amplitude because the rainfall variations associated with large-scale phenomena typically have a time scale longer than 2 mo [17]. For the Nino 3.4 index, a 3 mo running mean is calculated to more effectively isolate variability closely related to the ENSO phenomenon. The most significant negative correlations were between mode 2 from October-November and the Nino 3.4 index obtained from the preceding June to the following May. The spatial pattern of mode 2 (Figure 2(b)) shows positive and negative values to the east and west of the CMR. The negative correlation between PC2 and Nino 3.4 means that it is wetter in eastern than in western Taiwan and drier in eastern than in western Taiwan during La Niña and El
Niño years, respectively. This observation indicates that after a mature phase of El Niño years, the western part of Taiwan is wetter than the eastern part is.

To demonstrate the wind variance associated with the most significant correlations between PC2 (October to November) and Nino 3.4 (from the preceding June to the following May, Figure 6(a)), Figure 6(b) shows the regression map of the second EOF averaged from October to November against an $850 \mathrm{mb}$ wind stress averaged from September to November in the same year. The interannual variations of EOF2 were correlated with a cyclonic circulation anomaly over the South China Sea (SCS) and the anomalous easterly wind over the tropical western-central Pacific and westerly over the southern SCS and the Indian Ocean in the ongoing year. Figure 6(c) is the same as Figure 6(b), except that the wind speed is now a 3-month average, from December to February in the following year. The result indicates that a strong EOF2 during autumn was correlated with the enhanced anomalous winter northeasterly monsoon that is associated with an anticyclonic circulation anomaly over the Philippine Sea.

Figure 7(a) plots the correlation coefficients between the 2-month PC3 and the 3-month running mean PDO index obtained from the current year to the following year. The most significant positive correlations were between mode 3 from February-April and the Nino 3.4 index obtained from the preceding March to June. Figure 7(b) shows the regression map of the third mode averaged from February to March against the $850 \mathrm{mb}$ wind stress averaged from January to March in the same year. The anticyclonic circulation anomaly over the Philippine Sea that is associated with the interannual variation of springtime rainfall in northern Taiwan agrees with the report of Hung et al. [10], who related this anomalous circulation to the PDO phase. 


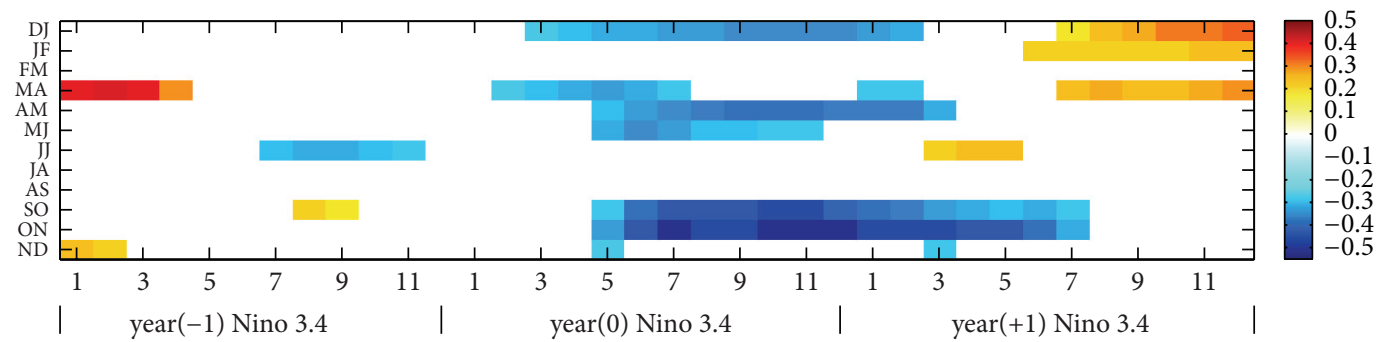

(a)

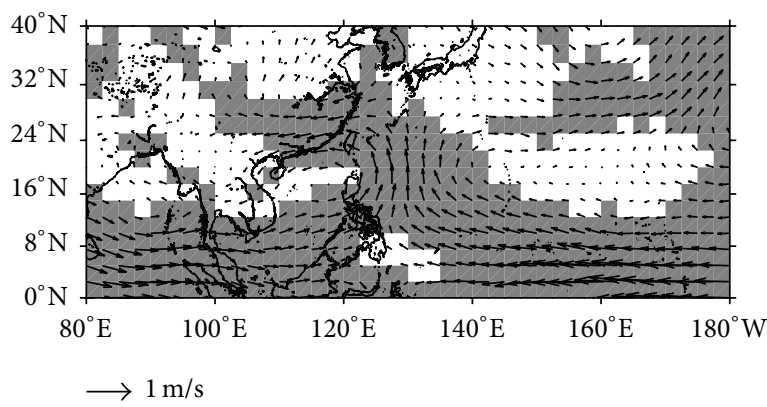

(b)

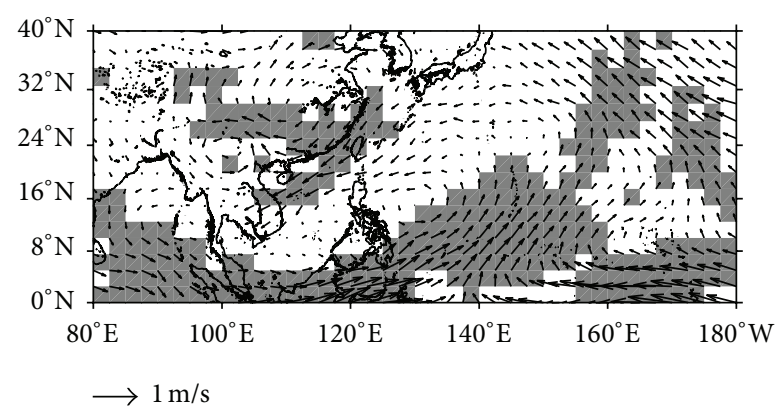

(c)

FIgURE 6: (a) Correlation map between 2-month mean EOF2 and Nino 3.4 index (significant at the 95\% level). (b) Regression map of EOF2 averaged from October to November against $850 \mathrm{mb}$ wind averaged from September to November in the concurrent years. (c) Regression map of EOF2 averaged from October to November against $850 \mathrm{mb}$ wind averaged from December to February in the following years. Shaded areas exceed the $95 \%$ confidence level.

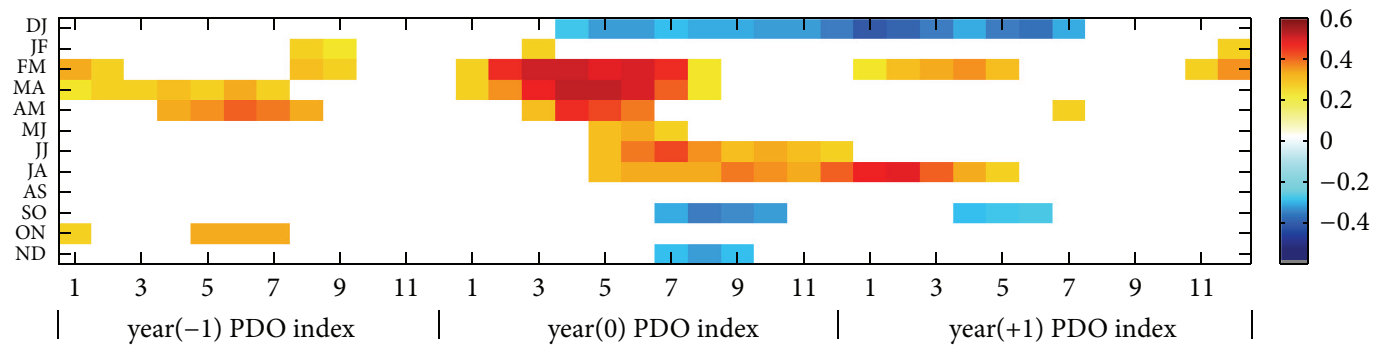

(a)

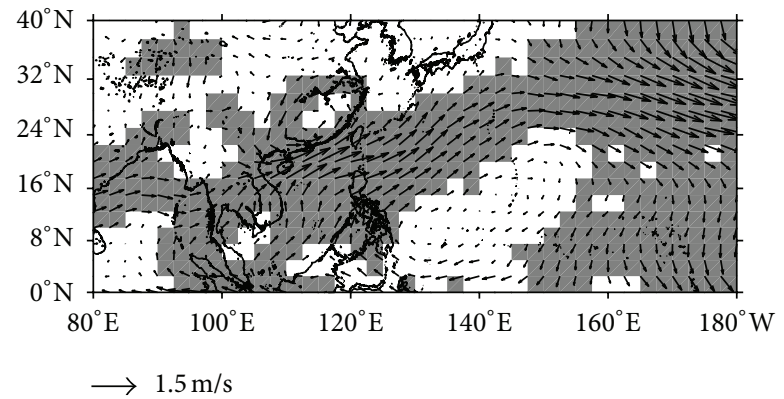

(b)

Figure 7: (a) Correlation map between 2-month mean EOF3 and PDO index (significant at the 95\% level). (b) Regression map of EOF3 averaged from February to March against $850 \mathrm{mb}$ wind speed averaged from January to March in the concurrent year. Shaded areas exceed the $95 \%$ confidence level. 


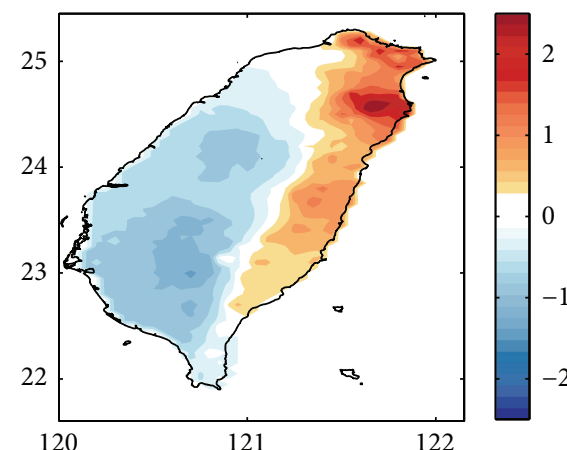

(a)

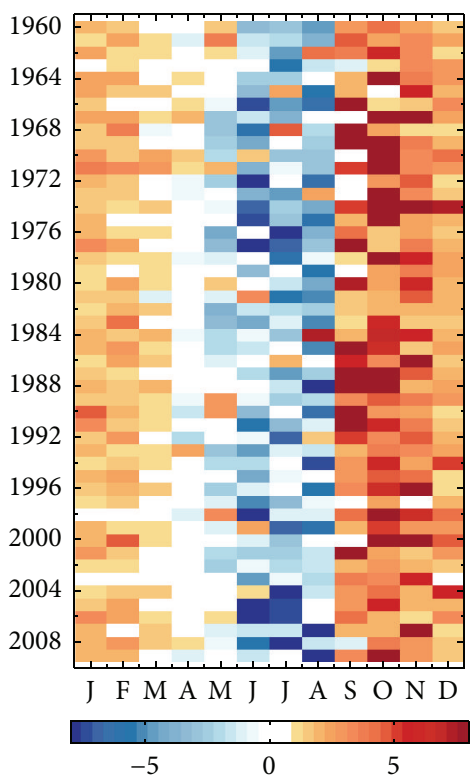

(c)

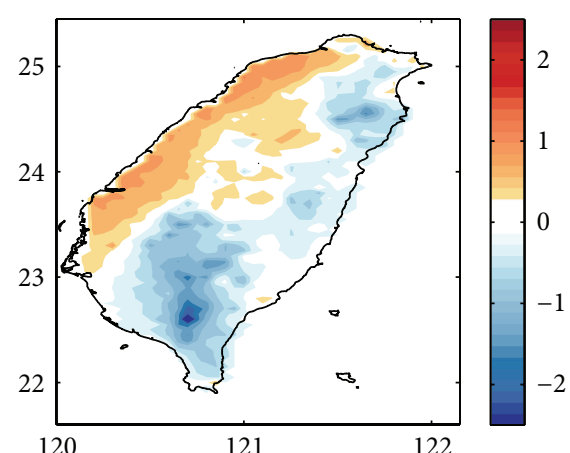

(b)

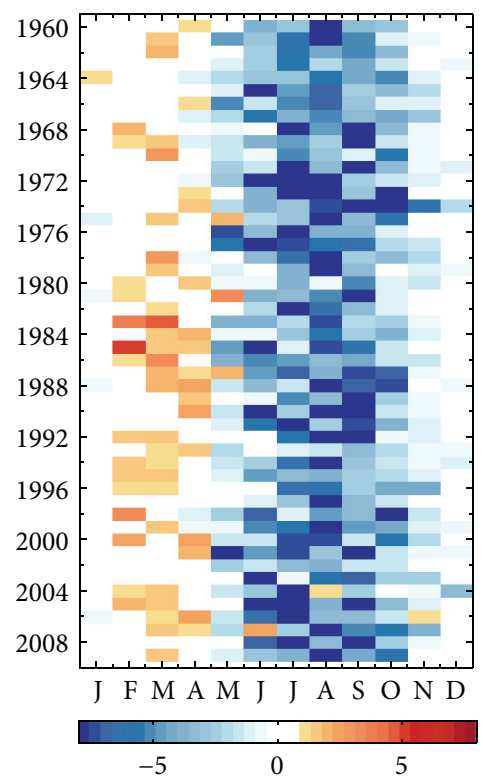

(d)

FIGURE 8: (a)-(b) Spatial EOF mode 1 and mode 2 patterns; (c)-(d) the corresponding amplitudes of the spatial EOF.

3.3. Spatial EOF Result. The results of spatial EOF analysis are presented in Figure 8. The first two modes can explain $61 \%$ of the total spatial variance, and the first mode $(40 \%)$ showed a northeast-southwest out-of-phase pattern featuring the highest value in the northeastern region of Taiwan. This indicates that the largest spatial variance is associated with the seasonal monsoon transition and the interaction between monsoon and topography. A seasonal oscillation was detected in the time series of the first mode (Figure $8(\mathrm{~b})$ ). The amplitude was prominent during the three strong La Niña years (1974, 1989, and 1998), as it was in the time series of the temporal EOF second mode. In addition to exhibiting the peaks that might be associated with ENSO events, the magnitude has been increasing since 2005. The spatial EOF second mode $(21 \%)$ reveals the difference in rainfall between the plain areas and windward mountain slopes. The seasonal variation of the second mode indicates higher rainfall in mountainous area than those in plain areas during summer to fall, which were associated with typhoons crossing the region. The critical role that the uplift of the extremely large moisture flux plays in producing heavy rainfall is widely established [18-20]. However, the loading amplitude was the opposite during spring, indicating positive (negative) rainfall variance in the plain area (mountainous area).

Figure 9 plots the linear-regression map of the global annual average SSTs against the annual average of the first and second spatial EOF modes. The pattern of the firstmode regression map is similar to that shown in Figure 5(b), resembling the SSTA corresponding to ENSO events. The second-mode regression pattern showed that the relationship was significant in the midlatitude region, resembling a PDO positive phase pattern. This result seems consist with J.M. Chen and H.-S. Chen's [11] observation of similarities between the PDO index and typhoon rainfall in Taiwan from June to August. However the local rainfall variability associated with typhoons is not only modulated by the PDO on a decadal time scale and further study is required to explore the regulating processes relating to the large-scale ocean-atmosphere modes. 


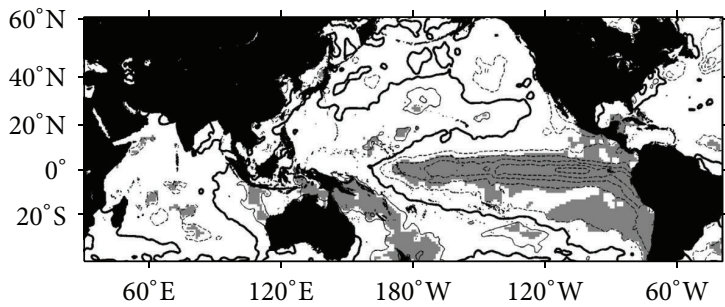

(a)

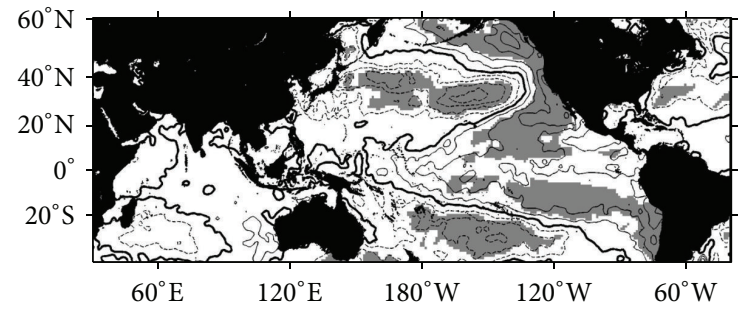

(b)

FIgURE 9: It is the same as Figure 5 but for (a) spatial EOF mode 1 and (b) spatial EOF mode 2.

\section{Discussion}

4.1. Comparison with Previous EOF Research. Yen and Chen [5] studied the seasonal transition of the rainfall pattern in Taiwan using the EOF method. In the present study, we collected monthly data from 15 coastal stations during the period of 1981 to 1997 . We extracted the 1981-1997 data from our gridded data to compare the differences in the EOF result (not shown). Our results agree with those shown in Figure 2 in the report of Yen and Chen (2000). However, because more data were collected in our study than in the previous study, especially in the mountain areas, the contributions made by the first mode (78\%) and the second mode (17\%) in this report were higher and lower, respectively, than those (58\% and 34\%, resp.) of Yen and Chen [5]. Previous studies have demonstrated that the interactions between seasonal monsoons, tropical storms, and the topography of Taiwan could greatly amplify local rainfall [18-20]. Because the lowlevel circulation in Taiwan area is modified by large-scale climate variability, we can infer that the orography amplifies the rainfall response to large-scale phenomena variability.

4.2. Large-Scale Climate Variability. The East Asian monsoon and its interaction with the topography of Taiwan resulted in a rainfall anomaly pattern. The CMR played a critical role in the rainfall distribution. In addition, the rainfall pattern of the spatial EOF1 is similar to the temporal EOF2, indicating that the northeast-southwest out-of-phase pattern was the dominant spatial variance. In addition, the correlations between temporal EOF2 and SST resembled a pattern of the ENSO phenomenon.

The most significant correlation between EOF2 and the Niño 3.4 index was observed between the mean of EOF2 from October to November and the Niño 3.4 index from June in the ongoing year to April in the following year (Figure 6(a)). The anomalous easterly wind over the tropical westerncentral Pacific and the westerly over the tropical Indian Ocean during autumn (September to November) associated with the temporal EOF2 consisted of a wind circulation pattern typical of the developing La Niña period (Figure 6(b)). In addition, an anomalous cyclone also correlated with the temporal EOF2. The cyclonic circulation enhanced the moisture flux coming from the Pacific Ocean toward Taiwan. The southerly extending from the eastern flank of anomalous cyclones causes tropical cyclones to move northwestward toward the open oceans to the southwest of Taiwan.
The three peak values of the positive phase of the temporal EOF2 coincided with the La Niña years following an El Niño period. Chao et al. [21] found that, during a weaker northeasterly monsoon year such as an El Niño event, warm water tends to accumulate in the southern SCS. Thus, when northerly winds relax in spring, warm water returns northward, resulting in an enhanced spring warm pool (SWP) in the central SCS. Consequently, the anomalous cyclone shown in Figure 6(b) might be a regional atmospheric response to a local positive SST anomaly. The characteristics underlying this mechanism warrant further study. On the other hand, Kug and Kang [22] suggested a feedback process in which the warming in the Indian Ocean during the mature phase of an El Niño produces an anomalous easterly over the western edge of the Pacific, facilitating a fast transition to a La Niña.

As shown in Figure 6(c), during the developed La Niña winter, the response of the western Pacific to the SST anomaly over the tropical central-eastern Pacific is a cyclonic circulation anomaly over the Philippine Sea [7, 8]. This cyclonic circulation anomaly couples with the East Asia winter monsoon and further intensifies it. Wang et al. [7] used atmospheric general circulation models to demonstrate that, during El Niño years, an anomalous lower-tropospheric anticyclone located in the Philippine Sea formed as a result of a Rossby-wave response to suppressed convective heating, which is induced by both the in situ SST cooling and the subsidence forced remotely by the central Pacific warming. This anomalous anticyclone reduced the strength of the East Asia winter monsoon. By contrast, during the La Niña year, an anomalous lower-tropospheric cyclone located in the western North Pacific was observed [15].

Consequently, the autumn climate in Taiwan associated with ENSO exhibited substantial spatial variation because of the terrestrial effect. The climate variability associated with ENSO was distinct from that in other regions of East Asia. For example, Li et al. [23] used a gamma distribution function estimated from the historical sequence of daily precipitation and reported that extreme precipitation along the southeast coast of China in autumn occurred significantly more frequently in El Niño years than that in non-El Niño years. Wu et al. [17] documented the tempospatial evolution of ENSO-related seasonal rainfall anomalies in East Asia by using NCEP-NCAR reanalysis and station rainfall data (including 4 stations in Taiwan). They found positive correlations in southern China in fall during the onset of El Niño. 
The anomalous low-level anticyclone developing over the SCS in fall and enhancing the moisture supply to southern China during the onset of El Niño was suggested to be responsible for the rainfall anomaly. By contrast, an anomalous cyclone during the onset of La Niña (Figure 6(b)) enhanced the moisture flux from the tropical western Pacific to the east of Taiwan.

PDOs are related to the rainfall variance presented by the third mode. According to the analyses of the third mode of the temporal EOF, rainfall increased in northern Taiwan and decreased in southern Taiwan in years where the PDO index was positive, and this trend was reversed in the years with a negative PDO index. Hung et al. [10] proposed that, during the warm PDO phase, the positive SSTAs over the tropical central-eastern Pacific that accompanied the enhanced Aleutian low and low SSTs in the extratropical North Pacific can induce a low-level anticyclonic anomalous flow over the Philippine Sea, resulting in the southwesterly anomalous winds toward the east of Taiwan and enhancing the trough extending southwestward from southern Japan to northern Taiwan.

\section{Conclusion}

In this paper, we describe the major decadal variations of rainfall in Taiwan between 1960 and 2009 based on the gridded monthly data produced by the TCCIP. The gridded data provided a clear view of the EOF pattern associated with the rainfall variance in Taiwan. The first mode of temporal EOF $(65 \%)$ revealed that the annual peaks of large rainfalls in the southwestern mountain area of Taiwan are associated with southwesterly monsoons and typhoons during summer. The second mode of temporal EOF (16\%) revealed a northeastto-southwest out-of-phase distribution, roughly separated by the CMR, demonstrating the association of rainfall with the monsoon and its interaction with the CMR slope. The rainfall pattern of the spatial EOF1 is similar to the temporal EOF2, indicating that the pattern was the dominant spatial variance. The interannual variation of the second mode indicated the influence of ENSO events. The climate variability associated with ENSO was distinct from that in other regions of East Asia. The third mode of temporal EOF (7\%) depicted a northsouth out-of-phase pattern with slowly evolving variations that were approximately in phase with the PDO. These climate variations related to the anomalies of large-scale airsea interaction in the Pacific might cause a substantial change in the low-level pressure field in East Asia. The regional topography further redistributes the rainfall.

\section{Conflict of Interests}

The authors declare that there is no conflict of interests regarding the publication of this paper.

\section{Acknowledgments}

This study was part of Taiwan Integrated Research Program on Climate Change Adaptation Technology (TaiCCAT), sponsored by the grants from the National Science
Council of Taiwan, NSC101-2625-M-019-006 and 102-2811M-019-001. A special note of thanks is due to Dr. C. T. Shih for generous guidance through the revision process. The rainfall data were provided by the TCCIP (Taiwan Climate Change Projection and Information Platform Project; http://tccip.ncdr.nat.gov.tw/NCDR/main/index.aspx).

\section{References}

[1] C.-S. Chen and J.-M. Huang, "A numerical study of precipitation characteristics over Taiwan island during the winter season," Meteorology and Atmospheric Physics, vol. 70, no. 3-4, pp. 167-183, 1999.

[2] C.-S. Chen and Y.-L. Chen, "The rainfall characteristics of Taiwan," Monthly Weather Review, vol. 131, no. 7, pp. 1323-1341, 2003.

[3] G. T.-J. Chen, "Mesoscale features observed in the Taiwan MeiYu season," Journal of the Meteorological Society of Japan, vol. 70, pp. 497-516, 1992.

[4] C. H. Wang, L. A. Li, and W. C. Liu, "Some characteristics of the precipitation in Taiwan," in Biodersity and Terrestrial Ecosystem, C. I. Peng and C. H. Chou, Eds., Academia Sinica Monograph Series no. 14, pp. 343-354, Institute of Botany, 1994.

[5] M.-C. Yen and T.-C. Chen, "Seasonal variation of the rainfall over Taiwan," International Journal of Climatology, vol. 20, no. 7, pp. 803-809, 2000.

[6] T.-C. Yeh, "Typhoon rainfall over Taiwan area: the empirical orthogonal function modes and their applications on the rainfall forecasting," Terrestrial, Atmospheric and Oceanic Sciences, vol. 13, no. 4, pp. 449-468, 2002.

[7] B. Wang, R. Wu, and X. Fu, "Pacific-East Asian teleconnection: how does ENSO affect East Asian climate?" Journal of Climate, vol. 13, no. 9, pp. 1517-1536, 2000.

[8] B. Wang and J. C. L. Chan, "How strong ENSO events affect tropical storm activity over the western North Pacific," Journal of Climate, vol. 15, no. 13, pp. 1643-1658, 2002.

[9] Z. Jiang, G. T.-J. Chen, and M.-C. Wu, "Large-scale circulation patterns associated with heavy spring rain events over Taiwan in strong ENSO and Non-ENSO years," Monthly Weather Review, vol. 131, no. 8, pp. 1769-1782, 2003.

[10] C.-W. Hung, H.-H. Hsu, and M.-M. Lu, "Decadal oscillation of spring rain in northern Taiwan," Geophysical Research Letters, vol. 31, no. 22, Article ID L22206, 4 pages, 2004.

[11] J.-M. Chen and H.-S. Chen, "Interdecadal variability of summer rainfall in Taiwan associated with tropical cyclones and monsoon," Journal of Climate, vol. 24, no. 22, pp. 5786-5798, 2011.

[12] C. Simolo, M. Brunetti, M. Maugeri, and T. Nanni, "Improving estimation of missing values in daily precipitation series by a probability density function-preserving approach," International Journal of Climatology, vol. 30, no. 10, pp. 1564-1576, 2010.

[13] C. A. Glasbey and I. M. Nevison, "Rainfall modelling using a latent gaussian variable," in Modelling Longitudinal and Spatially Correlated Data, vol. 122 of Lecture Notes in Statistics, pp. 233242, Springer, 1997.

[14] S.-P. Weng and C.-T. Yang, "The construction of monthly rainfall and temperature datasets with $1 \mathrm{~km}$ gridded resolution over Taiwan Area (1960-2009) and its application to climate projection in the near future (2015-2039)," Atmospheric Sciences, vol. 40, pp. 349-370, 2012 (Chinese). 
[15] C. Torrence and G. P. Compo, "A practical guide to wavelet analysis," Bulletin of the American Meteorological Society, vol. 79, no. 1, pp. 61-78, 1998.

[16] N. A. Rayner, D. E. Parker, E. B. Horton et al., "Global analyses of sea surface temperature, sea ice, and night marine air temperature since the late nineteenth century," Journal of Geophysical Research, vol. 108, no. 14, p. 4407, 2003.

[17] R. Wu, Z.-Z. Hu, and B. P. Kirtman, "Evolution of ENSO-related rainfall anomalies in East Asia," Journal of Climate, vol. 16, no. 22, pp. 3742-3758, 2003.

[18] X. Ge, T. Li, S. Zhang, and M. Peng, "What causes the extremely heavy rainfall in Taiwan during Typhoon Morakot (2009)?" Atmospheric Science Letters, vol. 11, no. 1, pp. 46-50, 2010.

[19] M. S. Peng and S. W. Chang, "Numerical forecasting experiments on Typhoon Herb (1996)," Journal of the Meteorological Society of Japan, vol. 80, no. 6, pp. 1325-1338, 2002.

[20] C.-C. Wu and Y.-H. Kuo, "Typhoons affecting Taiwan-Current understanding and future challenges," Bulletin of the American Meteorological Society, vol. 80, no. 1, pp. 67-80, 1999.

[21] S.-Y. Chao, P.-T. Shaw, and S. Y. Wu, "Deep water ventilation in the South China Sea," Deep Sea Research Part I: Oceanographic Research Papers, vol. 43, no. 4, pp. 445-466, 1996.

[22] J. S. Kug and I. S. Kang, "Interactive feedback between ENSO and the Indian Ocean," Journal of Climate, vol. 19, no. 9, pp. 1784-1801, 2006.

[23] W. Li, P. Zhai, and J. Kai, "Research on the relationship of ENSO and the frequency of extreme precipitation events in China," Advances in Climate Change Research, vol. 2, no. 2, pp. 101-107, 2011. 

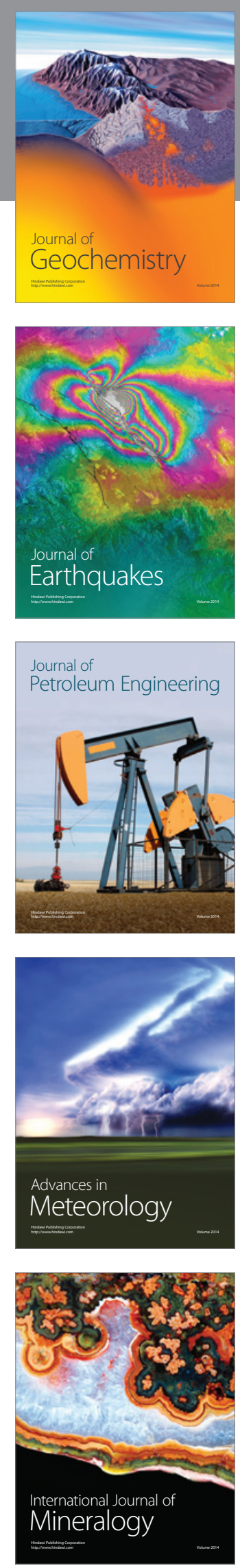
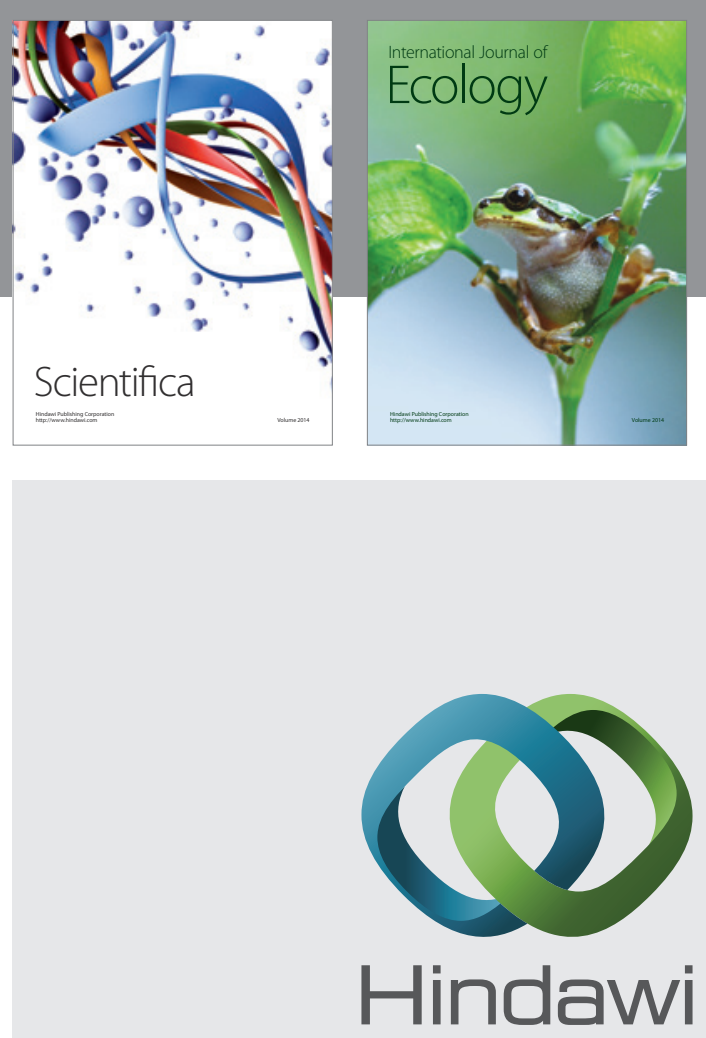

Submit your manuscripts at

http://www.hindawi.com
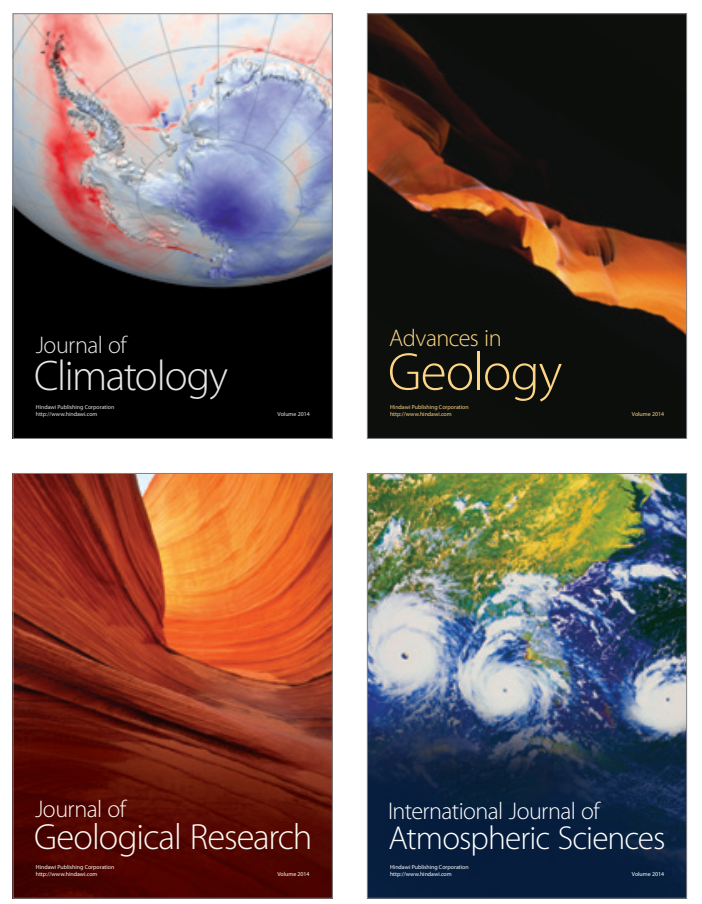

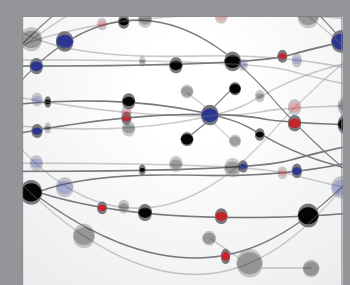

The Scientific

\section{World Journal}
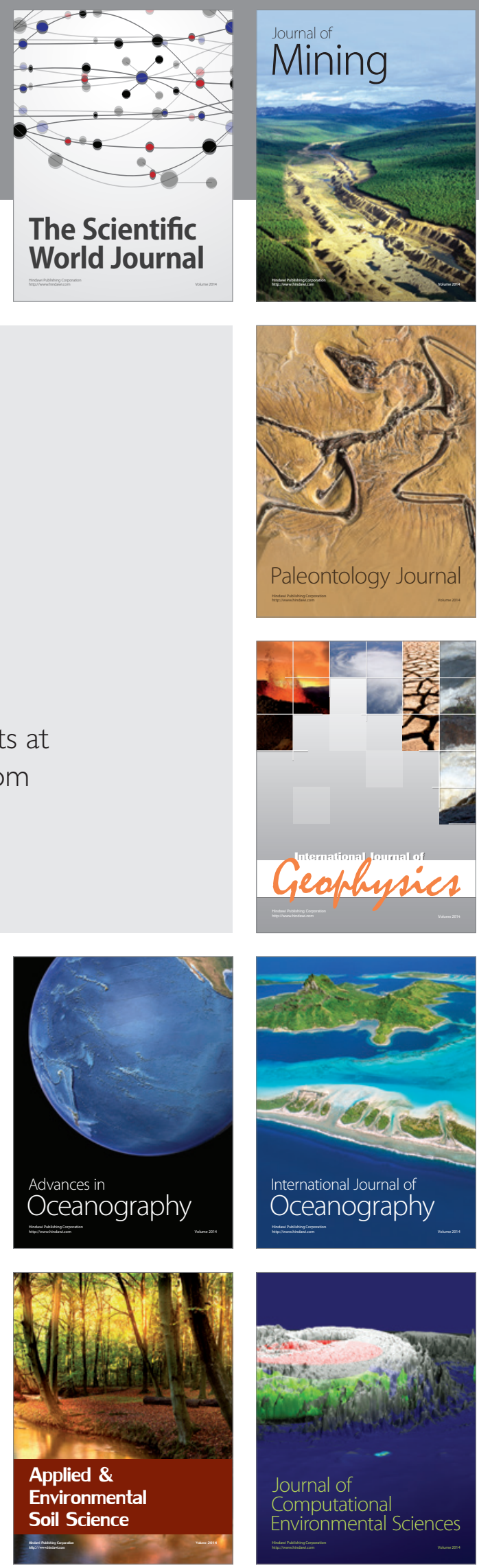